\title{
Improving the first year through an institution-wide approach: The role of first year advisors ${ }^{1}$
}

\author{
Lynn Burnett ${ }^{2}$ \\ University of Western Sydney
}

\section{Stephen Larmar \\ Griffith University}

\section{Abstract}

An example of a long term strategic development aimed at improving first year student engagement and retention in an Australian-based university is presented. One innovative practice has been the creation and implementation of the First Year Advisor (FYA) role, an academic position, situated at a degree level within the Faculties/Schools across the University. This paper presents vignettes of local level FYA initiatives as well as strategic institution-wide activity as an example of one approach which sought to engage in sustained first year student experience improvement.

\section{Please cite this article as:}

Burnett, L. \& Larmar, S. (2011). Improving the first year through an institution-wide approach: The role of first year advisors. The International Journal of the First Year in Higher Education, 2(1). 21-35. doi: 10.5204/intjfyhe.v2i1.40

This article has been peer reviewed and accepted for publication in Int J FYHE. Please see the Editorial Policies under the 'About' section of the Journal website for further information.

(C) Copyright of articles is retained by author/s. As an open access journal, articles are free to use, with proper attribution, in educational and other non-commercial settings. ISSN: 1838-2959

1 An earlier version of the paper was prepared as a refereed abstract for the 21st First Year Experience Conference, Dublin, 23rd-26th June, 2008.

2 Original work on this paper was conducted while the first author was employed at Griffith University as the University's First Year Advisor Coordinator. Significant work has been completed on subsequent versions since the author has been employed at The University of Western Sydney. 


\section{Introduction}

Understanding the first-year experience plays a critical role in managing transitions to tertiary study, in retaining students, and in setting up the educational foundations for academic success. (Krause \& Coates, 2008, p. 495)

The higher education sector in Australia has experienced spiralling attrition rates, major changes to Government funding and unprecedented massification (Bradley, Noonan, Nugent \& Scales, 2008; Kift, 2008; Krause, 2005, 2006). Increasingly, pressure is being placed on university staff (academic and professional) to retain first year students who previously may not have had an opportunity to enter tertiary studies. Greater efforts are being placed on getting first year student transition and sense of connection and engagement right in an effort to raise students' overall satisfaction with their undergraduate experience as well as increasing the likelihood of degree completion (Kift, 2008; Leese, 2010; Tinto, 2002, 2009; Yorke \& Thomas, 2003).

The innovative strategic approach presented in this paper was developed at Griffith University, a multi-campus public institution in South East Queensland, Australia. There are approximately 30,000 students enrolled across five campuses. Each campus is diverse in relation to its location, programs offered, and student cohort. The University offers a wide range of undergraduate and postgraduate degree programs across a range of disciplines. As a result of changes in the Australian higher education sector outlined previously, this particular university has taken a pro-active stance and embarked upon cultural change designed to enhance the quality of first year student experience and improve learning and teaching within the institution. These initiatives draw on work by Tinto (2009) who identified expectations, support, feedback and involvement as the four conditions necessary for quality student retention. The initiatives at Griffith have top-down support from senior administration (for example, Deputy Vice-Chancellor [Academic]), as well as bottom-up schemes which recognise, develop, and support the local capacity to work towards effective and collective institution-wide cultural shifts. National recognition of the growing success of the First Year Advisor (FYA) role and approach at Griffith was received in 2009 with nomination for and receipt of both an Australian Learning and Teaching Council (ALTC) Citation and National Program award.

This paper will explore the FYA initiative by beginning with the framework and strategies underpinning the role and practice including the Five Senses Framework (Lizzio, 2006a) and a Student Experience Model (Burnett, 2006). Strategies for facilitating strategic institution-wide change will be outlined as a means of understanding and engaging with this process. Finally a series of vignettes will be presented to illustrate the outworking of the FYA role as it applies to a range of local Faculty/School contexts.

\section{Framework and strategies underpinning the FYA role}

Early work began with the Griffith Retention Project (Lizzio \& Peters, 2004) and the instigation of multiple FYA roles held by academic members of staff within each of the University's four organisational groups in 2006 (Lizzio, 2006a, 2006b). Each of the FYAs is supported by their group Dean/Deputy Dean (Learning and Teaching). A framework was developed by Lizzio (2006a) which investigates the five 


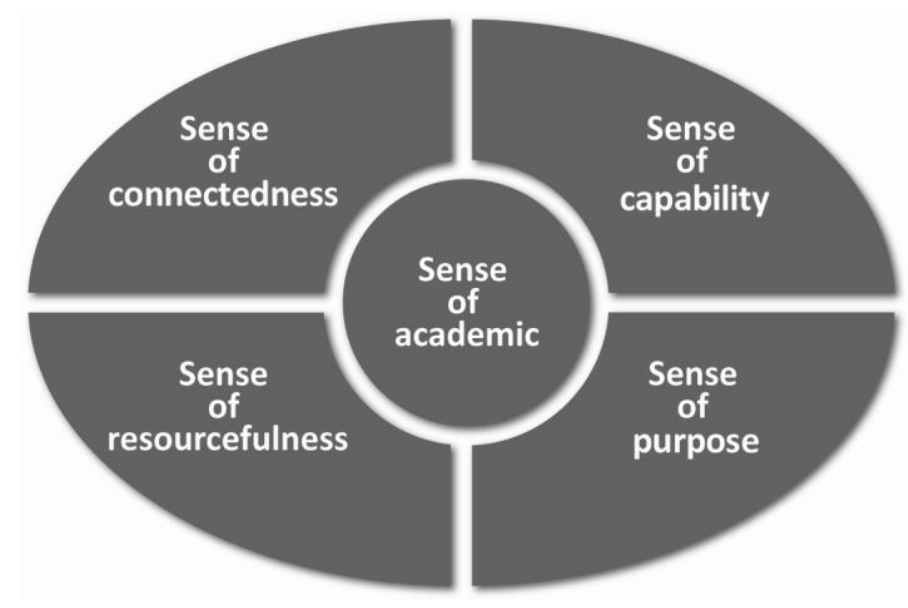

Figure 1 Coherent practice model-student process:

Five senses of success (Finger, 2007)

senses of success for students, staff and the institution. Each of the three areas of student, staff, and institutional activity and experience can be unpacked and understood in terms of the five senses of success and reflection, namely: developed senses of capability, connectedness, purpose, resourcefulness and academic culture (see Figure 1 from Finger, 2009). The framework connects complex bottomup and top-down activity and allows for multiple data points and inputs at the three levels of student, staff and whole-ofinstitution.

The model in Figure 1 illustrates how all five senses are connected, inform practice and experience, and provide a common language and understanding at the three levels of student, staff and institution. This framework is particularly useful for FYAs who are academic members of staff who understand and are interested in first year students, their issues and experiences.
FYAs are charged with the responsibility of:

1. helping students settle into their first year of university study;

2. assisting students to become selfmanaged learners and take responsibility for their studies and career;

3. facilitating orientation and on-going activities to support students at the local level;

4. engaging in the scholarship of learning and teaching, focusing particularly on the first year; and

5. providing leadership in enhancing the first year experience.

As a further means of supporting the FYAs, the appointment of an FYA University-wide Coordinator was made midway through 2007. Previously, the position was a fixed term seconded position facilitated by the 
Office of the Deputy Vice-Chancellor (Academic). The creation of a continuing FYA Coordinator position signalled a commitment by the University's senior management for ongoing support and growth of the FYA role within the University. The focus of this new role from the later part of 2007 until early 2010 was on developing appropriate structures, resources, and supports for greater impact of the FYA role within the University and ongoing practical planning and resource development.

Activities, resource development and support for FYAs in relation to enhancing the first year student experience, and ultimately improvement in institutionwide retention rates, was informed and supported by strategies including, but not limited to, the University's Planning and Quality Framework Assurance System; a large scale, systematic commencing students' survey (Student Orientation and Engagement Committee [SOEC], 2006, 2007, 2008, 2009); development and sharing of exemplars of best practice within the institution; and funding for attendance at the Pacific Rim First Year in Higher Education conferences in 2008 and 2009 to support FYA professional development and networking opportunities with the wider Australian first year experience arena.

The activities devised by the FYAs in a team approach with other teaching staff, Program Convenors, Course Convenors and support services at the local Faculty/School level were informed by and connected to the Five Senses Framework presented earlier developed by Lizzio (2006a) and the Student Experience Model (see Figure 2) designed by Burnett (2007) and discussed below. The notion of burden sharing instead of burden shifting has been

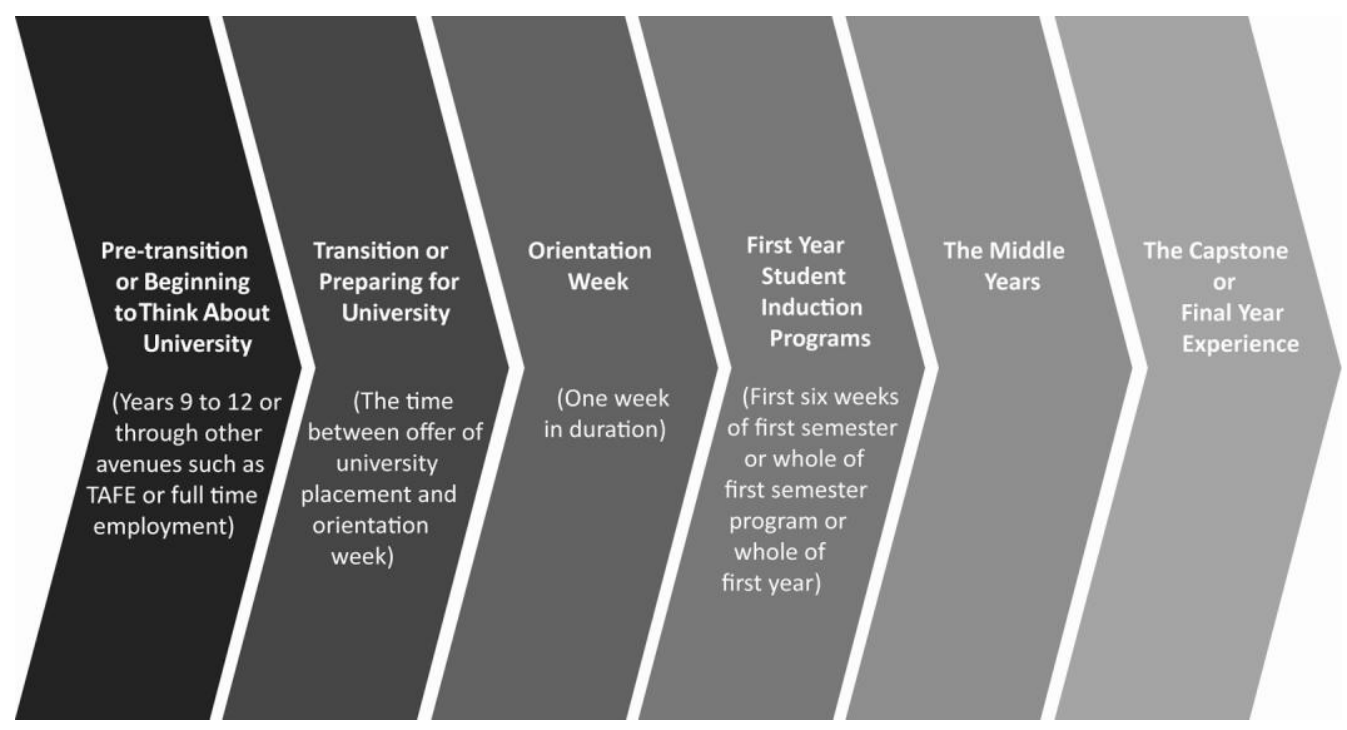

Figure 2 The student experience model

(with a focus on first year experience) (Burnett, 2007) 
widely discussed within the University as a result of ongoing refinements of the FYA role since its inception in 2006.

\section{The Student Experience Model}

The Student Experience Model (Burnett, 2007) identifies six key phases and provides an holistic view of understanding and enhancing the student experience with a focus on the first year student experience. A number of these phases actually occur outside the immediate university environment and well before first year students arrive on campus. These phases require and depend upon the fostering of strong and authentic community links.

Most established universities within Australia have a well developed suite of Orientation Week activities designed to ease student matriculation into higher education. Events in Orientation Week usually focus on social networking (for example, information and demonstrations by student clubs and societies, free barbeques, market days, and dance parties or concerts), academic skill development (for example, library and information technology sessions, time management courses, and essay writing information sessions), and specific program information (for example, welcome and information sessions either at a Faculty, School or program level). Current research in the area of first year experience recognises that while well organised and planned Orientation Week information and activities are essential in welcoming beginning students into university culture, more sustained and program-driven activity which provide "just-in-time" information is needed for successful transition such as the work currently being undertaken by FYAs at Griffith (Krause, 2006; Leese, 2010).

\section{Strategies for facilitating strategic institution-wide change}

There are many strategies which one can use to bring about long lasting positive institution-wide change with a view to enhancing the first year student experience. Based on earlier work by Burnett (2006), the most important include a coordinated and well developed plan of action and communication with whole-of-staff buy-in which is evidence-based and scholarly; processes for recognising and identifying good practice; funding to grow initiatives at the local level; systematic recognition and measurement of impact (local and institution-wide); authentic support from a high-level champion; recognition of and support for advance standing and postgraduate students; and a studentfocused model (see Figure 2) which recognises the need to engage in learner-centred proactive initiatives and activities.

This section examined a series of connected strategic institution-wide change processes that supported the development and implementation of the FYA role. The following section will present a series of vignettes of FYA activity from a local Faculty/School perspective as a means of illustrating the range of distinctive activities which take into consideration the unique culture and student cohort within each respective organisational group.

\section{Organisational structure of groups}

The University's four organisational groups (Arts, Education and Law including the Queensland College of Arts and Queensland Conservatorium of Music; Business; Health; and Science, Environment, Engineering and 


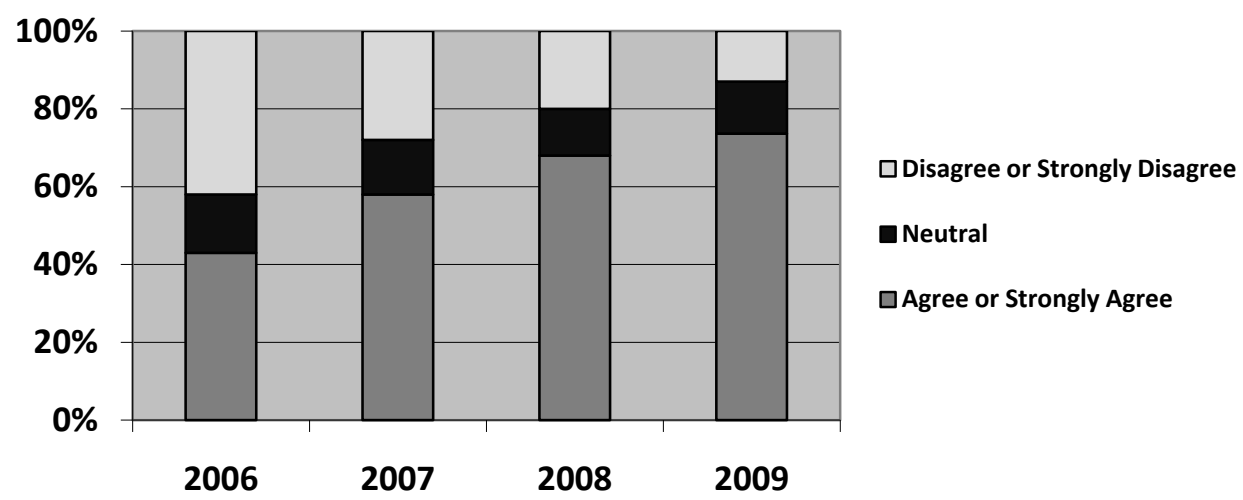

Figure 3 Sense of resourcefulness-Awareness of staff in key roles, university-wide: "I know the First Year Advisor for my degree program"

Technology) have established the FYA role within different timeframes. Each of the groups has identified varying needs, issues and student cohorts that have informed and shaped work at the local level. Given this, the FYA role has been uniquely performed within each group context and not surprisingly has varying levels of integration and acceptance. However, data from the SOEC surveys $(2007,2008,2009)$ indicate increased recognition of and connection with the FYA role from the student perspective and denotes success in staff efforts in getting commencing student transition and sense of connection with the institution and discipline to fit (see Figure 3).

\section{Arts, Education and Law group}

The Arts, Education and Law group is the largest of the four organisational groups and is spread across each of the five campuses. It also includes the Queensland College of Art and the Queensland Conservatorium of Music. In an effort to capture the uniqueness of the five sub-groups, each will be briefly explored with a vignette of FYA activities in Criminology.

The Arts sub-group is located across four of the five campuses. It prides itself in offering a range of distinctive and innovative multidisciplinary programs in Humanities, Social Science, Criminology, Languages and Creative Arts. While there is consistency in programs offered on multiple campuses, each maintains a uniqueness which reflects the characteristics and needs of the local students and campus (see Vignette 1). 


\section{Vignette 1 Holistic and team approach to first year in Criminology}

The FYA in the School of Criminology and Criminal Justice has designed a holistic academic orientation process for first year students which extends beyond the traditional Orientation Week program. This process collaborates with and integrates staff across the university, connects with later year students and graduates, and is embedded within Lizzio's (2006a) Five Senses Framework. This extended academic orientation program includes:

School Orientation Week Committee-The FYA chairs this committee and assures two formal orientations occur throughout each academic year. These orientations make sure commencing students are introduced to School academic and support staff, student services, learning services, information technology, welfare and careers and security and facilities. Activities are an integral part of the orientation and are designed to foster and build peer relationships, familiarity with the campus, and develop strategies for surviving at university.

First Year Management Team-A first year management team has been initiated by the FYA to ensure consistent information and messages are given to first year students. This team involves key stakeholders within the School and from central service units. The team meets regularly throughout the year to coordinate curriculum design, review, and assessment.

First Year Student Support System-This system allows the FYA to consult regularly with Course Convenors and model supportive strategies appropriate for all students, but particularly first year students. The FYA is able to identify at-risk students early (i.e. those who fail to submit assessment items) and bring them to the attention of the appropriate Course Convenor. These students are followed-up and contacted by telephone or face-toface.

CSI (Criminology Students Investigating) - CSI is a zero credit point course deliberately designed to offer support, clarify student/staff expectations, and introduce students to research skills and self-directed inquiry. In 2008, the FYA was able to invite third year Applied Theatre Education Drama students to the CSI session. These later year students role play just-in-time issues pertinent to first year students throughout the first semester.

Throughout 2008, the FYA has also developed and commenced tutor training each semester for Tutors and Course Convenors teaching directly into first year courses. This training is supported by a tutor training handbook adapted from a manual designed by the School of Psychology, Health Group. The FYA has also designed a systematic filing system for keeping notes on all students who could potentially be considered at-risk in the future. 


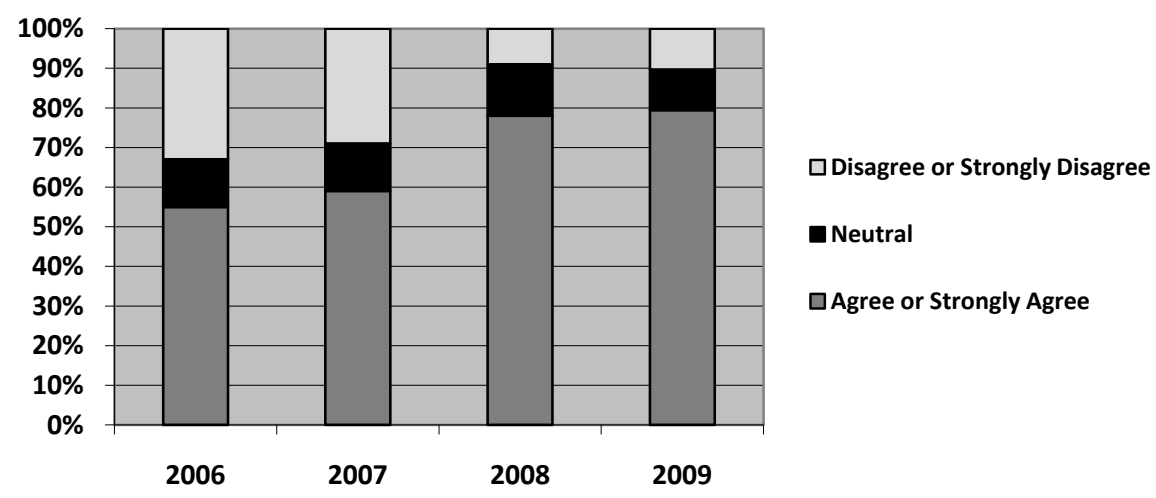

Figure 4 Sense of resourcefulness-Awareness of staff in key roles in Education: "I know the First Year Advisor for my degree program"

The Education sub-group is located at three campuses; a small boutique inner city suburban campus which was formerly a teacher's college, the largest growing campus based in a south-east corridor, and an outer suburban campus with the majority of students being the first in their family to attend university. Following the example set by the Health group, Education has actively embraced the FYA role and has been proactive in supporting and validating the important work being undertaken by their FYAs. They have identified three coherent practice metamessages for their work as FYAs: First, literature and evidence-base enables staff confidence and buy-in. The meta-message is that "we are approaching this in a scholarly and systematic way"; next, notions of shared language facilitates students' confidence in the system provide the basis for the meta-message of "we have really thought about this and we know what we are doing"; and finally, clearly articulated framework facilitates students' self-management leads to the meta-message of "we are not just giving you information - we are providing you with tools to do a job" (Finger, 2007, p. 2).

Regular forums and workshops were held where FYAs, following the University's Planning and Quality Framework Assurance System (PIRI ${ }^{3}$ Model), shared and reflected upon their practice, identified strategic areas which required combined effort, and developed new plans for future implementation. Their work is reflected in the Starting@Griffith survey data (SOEC, 2006, 2007, 2008, 2009) (see Figure 4).

The Law sub-group is spread across two campuses and encourages its students to combine their law studies with another discipline to ensure their cohort possess well-rounded knowledge, skill and practice. This sub-group is distinctive through its strong connections and partnerships with industry and community groups. There is a strong culture of diversity, inclusiveness and social justice.

\footnotetext{
${ }^{3}$ Plan, Implement, Review and Improve model.
} 
Queensland College of Art and Queensland Conservatorium of Music are predominantly based at the inner city campus. Some programs are also offered at the Gold Coast campus. Staff members across all year levels in both areas form close bonds with their students as a result of their respective discipline areas and as a result experience different issues in comparison to the other organisational groups.

\section{Business group}

The Business group is predominantly located on three campuses and emphasises the important relationship between business and society in promoting sustainable business practices and communities (see Vignette 2). This group has the highest proportion of international students in its cohort and also deals with extremely large class sizes.

\section{Health group}

The Health group have been the forerunners in proactively engaging with the FYA role. The Dean (Learning and Teaching) has been able to secure annual funding from the group specifically to support FYA initiatives (see Vignette 3).
Regular local level FYA forums are held throughout the year where FYAs share their activities and experiences, explore future plans, and submit annual written applications for funding. A full-time Learning Development Officer is also employed and is central in supporting the Dean (Learning and Teaching) and FYAs across the four campuses. There are more than 5,000 students enrolled in multidisciplinary programs across the Health group. Results from the Starting@Griffith survey (SOEC, 2006, 2007, 2008, 2009) show impressive increased improvements and recognition of FYAs (see Figure 5). It is recognised within the University that these results are because of the focused, considered and coordinated whole of group approach taken with first year. The Health group have willingly shared their strategies and approaches with other groups within the institution and work undertaken by the Education sub-group presented earlier in this paper is testimony to this leadership.

\section{Vignette 2 Early connections with industry program}

In 2008 with the advent of a new suite of accelerated and professional business programs, the FYA at the Logan campus designed and implemented a three day Orientation Program. The program managed student/staff expectations, developed strategies for academic skill development, facilitated peer networking and linked commencing students with industry mentors at a professional breakfast function. An internship program for students in the professional suite was also incorporated into the 3 day orientation. A series of ongoing professional development days are planned throughout the year to extend on activities and concepts introduced in the Orientation Program. This program was nominated for and won a prestigious 2010 ALTC award. 


\section{Vignette 3 Common time}

The FYA in the School of Human Services and Social Work has worked with key staff involved in the first year Bachelor of Human Services and Social Work programs to enhance the matriculation of first year students. A key strategy that underpins the first year orientation and engagement plan of the school is the common time program. Common time is a weekly forum for first year students focussed on developing greater cohesion within the first year cohort and exploring generic skills critical to academic success.

Common time is designed to provide students with social and academic support within a flexible learning environment to assist their transition into University and their integration into the Human Services programs. Students and first year staff meet at a designated time and place each week and follow a semi-structured program that provides both formal didactic instruction and less formal whole and small group activities focussed on the first year experience. Students' skills and knowledge in areas such as essay writing, oral presentations, information skills and professional development are enhanced through a mixture of structured and informal academic and professional sessions which include guest speakers from the Human Services fields. A key emphasis of the common time strategy is to provide opportunity for students to establish peer networks and consult with teaching staff in a safe and supportive environment.

In a recent survey developed to examine the efficacy of the common time approach, students reported that their initial experiences within the School of Human Services were significantly enhanced as a result of their engagement in common time. Specifically, students indicated that common time provided a regular space where students could interface with one another, meet collectively and one-on-one with first year teaching staff and discuss common concerns relating to their studies. The School of Human Service's FYA and first year teaching staff are committed to facilitating ongoing evaluations of common time to ensure that it continues to assist students as a key strategy to promote active engagement within the school and the broader university culture. 


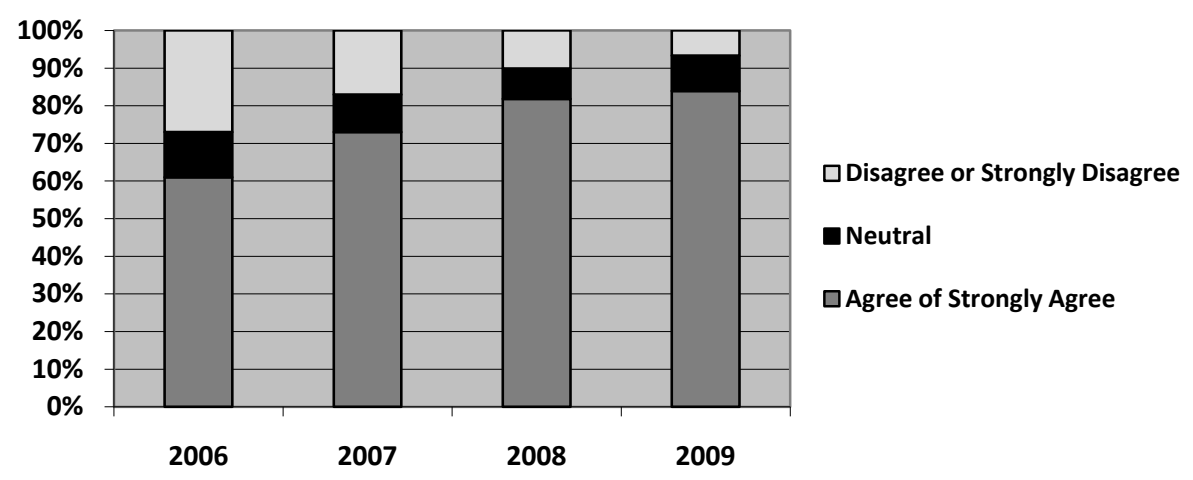

Figure 5 Sense of resourcefulness - Awareness of staff in key roles in Health: "I know the First Year Advisor for my degree program"

\section{Science, Environment, Engineering, and Technology (SEET) group}

The SEET group has over 4,000 students enrolled and is located across three campuses. As a result of the range of disciplines and campus locations, engagement with the FYA role has been varied. However, excellent work has been undertaken by many FYAs (see Vignette 4).

\section{Deliberations and conclusion}

One of the reasons students find transition to university so tumultuous is that it often challenges existing views of self and one's place in the world. ... Transition is a time of re-shaping and coming to terms with whether expectations about university life have been met, or need to be revised, or, in fact, if the mismatch between expectation and reality is too great to warrant persistence. ... The well-established argument for the importance of academic staff involvement in the lives of undergraduate learners early and often, both within and beyond the classroom [cannot be under-estimated]. (Krause \& Coates, 2008, p. 500)

Griffith University's FYA initiative, in conjunction with the Five Senses Framework (Lizzio, 2006a) and work by Tinto (2009), provides a cogent suite of strategies for proactive engagement with first year students to enhance the first year student experience and retention at the macro, meso, and local levels. The implementation of the FYA role at Faculty/School level has been pivotal in the described practice of engaging in an institution-wide change capable culture (Scott, 2004; Scott, Coates \& Anderson, 2008). While take-up of the FYA role has varied among the University's four organisational groups, those that have been proactive are accumulating strong long-term evidence about the impact of their practice and engagement with students; clearly supported in results from the Starting@Griffith survey (SOEC, 2006, 2007, 2008, 2009) and the vignettes provided. Practical support and recognition of the importance of the FYA 
role has also yielded other positive results in the form of FYA Learning and Teaching awards (for example, in 2007 a prominent FYA received the Prime Minister's National Award for University Teacher of the Year and in 2009 the program received both an ALTC Citation and National Program award), early work towards career recognition and pathways, and the development of a community of practice which engages with the Scholarship of Learning and Teaching.

The approach and vignettes presented here support research (see for example, Yorke \& Thomas, 2003; Zepke, Leach \& Prebble, 2006) which indicates institutions with programs focused on a student-centred approach to success rather than attrition rates are more successful because they recognise there are multiple and complex reasons why undergraduate students fail to complete their undergraduate studies. Zepke et al. (2006, p. 598), suggest that a learner/student-centeredness approach "improves retention where students feel they belong in an institutional culture, where they experience good quality teaching and support for their learning and where their diverse learning preferences are catered for." And work by Krause and Coates (2008) identify programs which concentrate on student engagement and relationship building with the institution, such as the FYA initiative, as pivotal in establishing the foundations for future student success.

This paper has presented and connected the FYA initiative with cogent frameworks and strategies which have underpinned the role and practice and led to positive long term institutional change. A synopsis of Lizzio's (2006a) Five Senses Framework was presented and connected with the Student Experience Model (Burnett, 2006) to illustrate the connection between philosophical assumptions undergirding the FYA role and everyday practice. A range of strategies were described that influenced strategic institution-wide change in relation to the FYA role. The paper concluded with a series of vignettes as a means of illustrating how the FYA role was operationalised across a range of contexts and student cohorts as an example of one Australian University's long term commitment to improving first year student experience.

\section{Acknowledgements}

The authors would like to thank Dr Fernanda Duarte, University of Western Sydney and Professor Kerri-Lee Krause from Griffith University for providing feedback on earlier drafts. Sincere thanks also to Dr Merrelyn Bates, A/Prof Paul Bates, and Dr Mark Brimble for sharing their FYA stories and activities. 


\section{Vignette 4 Building teamwork, leadership and skills}

The FYA in Aviation recognised the specific pilot requirements (for example, strong leadership, teamwork and analytical skills) needed by the airline industry and has spent the last 12 months developing and implementing an extra-curricular program to support and enhance student experience across all year levels with a specific focus on the first year.

In 2007, all students were randomly divided into flight groups, ensuring equal distribution of female students across the groups (female students make up approximately $20 \%$ of enrolments in this program). Each flight group is allocated a number of student leaders with one overall leader known as the Chief Student Pilot. Flight groups meet one night a week to organise activities, flight events, and participate in a public speaking activity. First year students are not graded on their public speaking as this activity is intended to allow them to practice their oral presentation skills in a safe environment and build their confidence. Topics for first year students begin with the familiar and progress to airlineor aviation-specific topics as the year progresses.

At the end of 2007, the flight groups decided to design a series of welcome events for the 2008 student cohort. One of these events eventuated into a peer mentoring program, Mentoring Aviators Through Educational Support (MATES). The mentoring program was introduced through a series of events designed and run by the later year students during Orientation Week. At the end of the Orientation Week, the first year students were asked to complete a questionnaire and there was a $100 \%$ return rate. Ninety percent of students felt more comfortable about university after participating in the MATES events during Orientation; Eighty-two percent of first year students felt their MATES mentor was helpful; Eighty-seven percent felt the small groups provided them with a sense of belonging to the program and the university; and $99 \%$ felt their initial questions and concerns about university had been answered and/or they knew where to go to get the information they needed. 


\section{References}

Bradley, D., Noonan, P., Nugent, H. \& Scales, B. (2008). Review of Australian higher education: Final report. Australia: DEEWR. Retrieved June, 2010 from www.deewr.gov.au/he_review_finalreport

Burnett, L. (2006). The first year experience project report. Brisbane, Australia: The University of Queensland.

Burnett, L. (2007, July). Juggling first year student experiences and institutional changes: An Australian experience. Paper presented at the 20th International Conference on First Year Experience, Hawaii, USA.

Finger, G. (2007). The Griffith Education first year experience project. Enhancing the student experience. Brisbane, Australia: Griffith University.

Finger, G. (2009). The Griffith Education first year experience project. Brisbane, Australia: Griffith University.

Kift, S. (2008, July). The next, great first year challenge: Sustaining, coordinating and embedding coherent institution-wide approaches to enact the FYE as "everybody's business." Keynote address presented at the 11th Pacific Rim First Year in Higher Education Conference, "An Apple for the Learner: Celebrating the First Year Experience." Hobart, Australia. Retrieved June, 2010, from http://www.fyhe.qut.edu.au/past_papers/pape rs08/FYHE2008/content/pdfs/Keynote\%20\%20Kift.pdf

Krause, K. (2005, October). The changing face of the first year: Challenges for policy and practice in research-led universities. Keynote address presented at The University of Queensland First Year Experience Workshop. Brisbane, Australia.

Krause, K. (2006, May). Transition to and through the first year: Strategies to enhance the student experience. Keynote address presented at The University of the Sunshine Coast Inaugural ViceChancellor's Learning and Teaching Colloquium.

Krause, K. \& Coates, H. (2008). Students' engagement in first-year university. Assessment \& Evaluation in Higher Education, 33(5), 493-505.

Krause, K., Hartley, R., James, R. \& McInnis, C. (2005). The first year experience in Australian universities: Findings from a decade of national studies. Centre for Studies in Higher Education, University of Melbourne, Australia.
Leese, M. (2010). Bridging the gap: Supporting student transitions into higher education. Journal of Further and Higher Education, 34(2), 239-251.

Lizzio, A. (2006a). Designing an orientation and transition strategy for commencing students. A conceptual summary of research and practice. First Year Experience Project. Brisbane, Australia: Griffith University.

Lizzio, A. (2006b). Enhancing the early learning environment for commencing students at Griffith University. A degree program based planning process. First Year Experience Project. Brisbane, Australia: Griffith University.

Lizzio, A. \& Peters, J. (2004). The retention project. Brisbane, Australia: Griffith University.

Pitkethly, A. \& Prosser, M. (2001). The first year experience project: A model for university-wide change. Higher Education Research \& Development, 20(2), 185-198.

Scott, G. (2007). Changing matters: Making a difference in higher education. Keynote address presented at AUQA Forum. Retrieved February, 2008, from

www.uws.edu.au/downlad.php?file_id=8569\&fi

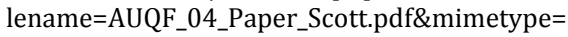
applicaiton/pdf

Scott, G., Coates, H. \& Anderson, M. (2008). Learning leaders in times of change: Academic capabilities for Australian higher education. An ALTC leadership project report. Sydney, Australia: Australian Learning and Teaching Council.

Student Orientation and Engagement Committee. (2006). Starting@Griffith 2006 survey. Brisbane, Australia: Griffith University.

Student Orientation and Engagement Committee. (2007). Starting@Griffith 2007 survey. Brisbane, Australia: Griffith University.

Student Orientation and Engagement Committee. (2008). Starting@Griffith 2008 survey. Brisbane, Australia: Griffith University.

Student Orientation and Engagement Committee. (2009). Starting@Griffith 2009 survey. Brisbane, Australia: Griffith University.

Tinto, V. (2002, June). Establishing conditions for student success. Paper presented at the 11th Annual Conference of the European Access Network, Monash University, Prato, Italy. Retrieved June, 2010, from http://www.wmin.ac.uk/can/wpm\$5de1.pdf 
Tinto, V. (2009, February). Taking student retention seriously: Rethinking the first year of university. Keynote address presented at the ALTC FYE Curriculum Design Symposium, Queensland University of Technology, Brisbane, Australia.

Yorke, M. \& Thomas, L. (2003). Improving the retention of students from lower socioeconomic groups. Journal of Higher Education Policy and Management, 25(1), 63-74.

Zepke, N., Leach, L. \& Prebble, T. (2006). Being learner centred: One way to improve student retention? Studies in Higher Education, 31(5), 587-600. 